\title{
A randomized clinical trial of prophylaxis in children with hemophilia A (the ESPRIT Study)
}

\author{
A. GRINGERI, * B. LUNDIN, $†$ S. VON MACKENSEN, ${ }^{*}+L$. MANTOVANI, $\$$ P. M. MANNUCCI* \\ and THE ESPRIT STUDY GROUP ${ }^{1}$ \\ *Department of Medicine and Medical Specialities, Fondazione IRCCS Cà Granda, Ospedale Maggiore Policlinico and University of Milan, \\ Milan, Italy; †Department of Radiology, University Hospital of Lund, Lund, Sweden; ¥Institute of Medical Psychology, University Medical Centre \\ Hamburg-Eppendorf, Hamburg, Germany; §Centre of Pharmacoeconomics, University Federico II of Naples, Naples; and $\uparrow$ Scientific Direction, \\ Fondazione IRCCS Cà Granda, Ospedale Maggiore Policlinico and University of Milan, Milan, Italy
}

To cite this article: Gringeri A, Lundin B, von Mackensen S, Mantovani L, Mannucci PM and The ESPRIT Study Group. A randomized clinical trial of prophylaxis in children with hemophilia A (the ESPRIT Study). J Thromb Haemost 2011; 9: 700-10.

Summary. Background: Prevention of arthropathy is a major goal of hemophilia treatment. While studies in adults have demonstrated an impact of prophylaxis on the incidence of joint bleeds and patients' well-being in terms of improved quality of life (QoL), it is unclear whether or not prophylaxis influences the outcome and perception of well- of children with hemophilia. Objective: This randomized controlled study compared the efficacy of prophylaxis with episodic therapy in preventing hemarthroses and image-proven joint damage in children with severe hemophilia A (factor VIII < $1 \%$ ) over a 10 -year time period. Methods: Forty-five children with severe hemophilia A, aged 1-7 years (median 4), with negative clinical-radiologic joint score at entry and at least one bleed during the previous 6 months, were consecutively randomized to prophylaxis with recombinant factor VIII ( $25 \mathrm{IU} \mathrm{kg}^{-1} 3 \times$ week) or episodic therapy with $\geq 25 \mathrm{IU} \mathrm{kg}^{-1}$ every $12-24 \mathrm{~h}$ until complete clinical bleeding resolution. Safety, feasibility, direct costs and QoL were also evaluated. Results: Twenty-one children were assigned to prophylaxis, 19 to episodic treatment. Children on prophylaxis had fewer hemarthroses than children on episodic therapy: 0.20 vs. 0.52 events per patient per month $(P<0.02)$. Plainfilm radiology showed signs of arthropathy in six patients on prophylaxis $(29 \%)$ vs. 14 on episodic treatment $(74 \%)(P<$ $0.05)$. Prophylaxis was more effective when started early $(\leq 36$ months), with patients having fewer joint bleeds ( 0.12 joint bleeds per patient per month) and no radiologic signs of arthropathy. Conclusion: This randomized trial confirms the efficacy of prophylaxis in preventing bleeds and arthropathy in children with hemophilia, particularly when it is initiated early in life.

Correspondence: Alessandro Gringeri, Via Pace, 9, Milan I-20122, Italy. Tel.: +3925503 5290; fax:+39255032072.

E-mail: alessandro.gringeri@unimi.it

Received 20 August 2010, accepted 29 December 2010

${ }^{1}$ For a complete list of the members of the ESPRIT study group see Appendix 1.
Keywords: episodic treatment, Haemo-QoL, hemarthrosis, hemophilia A, prophylaxis, quality of life.

\section{Introduction}

The most common hemorrhagic manifestations of hemophilia are recurrent hemarthroses, mainly in elbows, knees and ankles, which lead to a progressive joint destruction, irreversible crippling arthropathy and chronic pain [1]. Hence, prevention of arthropathy is the main goal of hemophilia therapy by means of the replacement of the deficient coagulation factor with concentrates, which can be administered episodically or regularly. Episodic therapy (i.e. the administration of concentrates on the occasion of bleeding) has been shown to decrease mortality and to slow the progression to arthropathy, but not to prevent it [2]. The long-term, regular, continuous administration of concentrates, based upon two to three or more weekly infusions, is the most effective method to forestall bleeding and bleeding-related complications [3], and therefore it was described as prophylaxis. A very early prophylaxis started before or at the time of the first bleed and within the second year of age, when joints are presumably still pristine, is called primary prophylaxis [4,5]. Prophylaxis started later is called secondary prophylaxis, because even after only a few bleeding episodes in the same joint, irreversible articular changes may have already occurred $[3,6]$.

There are barriers to early and long-term prophylaxis in children with hemophilia, mainly related to cumbersome venous access leading to inadequate patient/family compliance with the prescribed treatment. There are also important issues related to the need for considerable human and economic resources. The superiority of prophylaxis compared with episodic replacement therapy, apart from an obvious biologic rationale, had been based until recently on weak evidence [7]. The great majority of the studies were retrospective $[3,6]$ and the strongest but indirect evidence was provided by a longitudinal, uncontrolled, international cohort study carried out between 1986 and 1992 [8]. This study showed that a better 
orthopedic outcome was associated with a lower frequency of joint bleeds, and that continuous prophylaxis produced the best orthopedic outcome. Much stronger evidence on the efficacy of prophylaxis was provided in 2007 by the first prospective randomized study comparing prophylaxis and episodic therapy [9].

There are still several unresolved issues concerning prophylaxis in childhood: the efficacy in preventing arthropathy, particularly when prophylaxis is not started in the very first years of life; its feasibility in terms of compliance; venous access and complications related to indwelling catheters; the dosing regimen; cost-effectiveness; and effects on patients' quality of life (QoL) [10,11]. In order to answer these questions, we designed in 1996 a randomized controlled pragmatic trial, named ESPRIT (an acrostic from 'Evaluation Study on Prophylaxis: a Randomized Italian Trial'), with the goal of comparing the efficacy of prophylaxis with episodic therapy in preventing joint bleeds and arthropathy in children with severe hemophilia A (factor VIII, < $1 \%$ ) over a time period of 10 years, to help inform the choice between options for care [12]. The decision to employ a randomized controlled trial design was justified at that time by the fact that in the 1990s the standard care for patients in Italy, but also in the majority of other countries, was episodic therapy.

\section{Patients and methods}

\section{Study design}

We designed an independent, multicentre, parallel group, randomized, comparative, open, pragmatic trial, in order to evaluate whether or not prophylaxis was more effective than episodic therapy in preventing joint bleeding and joint damage in young children with severe hemophilia A. We chose an open study design because patient blinding was deemed unfeasible for ethical and practical reasons.

\section{Study objectives}

The hypotheses of the study were that prophylactic treatment of children with severe hemophilia A would (i) reduce the rate of bleeding and (ii) reduce the rate of joint damage. The study was designed to capture long-term effects of prophylaxis by means of a long follow-up. In addition, the study had the goal of comparing safety, feasibility, direct costs of health care, costeffectiveness and quality of life.

\section{Eligibility criteria}

All severe hemophilia A patients (FVIII activity level $<1 \%$ ), without measurable inhibitors $\left(<0.6 \mathrm{BU} \mathrm{mL} \mathrm{L}^{-1}\right)$, with an age ranging from 1 to 7 years, were candidates for inclusion in the study. Exclusion criteria were: any clinical or radiologic signs of joint damage, in order to exclude patients with already established arthropathy; no bleeding episodes in the previous 6 months, in order to exclude patients with mild bleeding frequency; a history of more than two bleeding episodes in the same joint or muscle, in order to exclude patients with already damaged joints not detected by clinical examination or imaging; concomitant severe chronic diseases or congenital skeletal malformations; and unreliability or likelihood of poor compliance with the long-term follow-up.

\section{Recruitment sites}

Eligible patients were consecutively recruited in 12 hemophilia comprehensive care centres of the 36 existing in Italy in 1996; these centres were uniformly distributed all over the country (a list of the centres is provided in Appendix 1). The study protocol and patient information sheet were approved by the Institutional Review Board of each participating centre. Parents or legal guardians of eligible patients gave written informed consent.

\section{Randomization and treatments}

Patients were randomly assigned following a centralised, simple randomisation procedure (computerised random numbers), to be treated on prophylaxis with a first generation recombinant FVIII concentrate (rFVIII; Recombinate ${ }^{\circledR}$, Baxter, Deerfield, IL, USA) at the dose of $25 \mathrm{IU} \mathrm{kg}^{-1}$ three times a week on nonconsecutive days, or episodically (i.e. at the time of occurrence of a bleeding event) with the same product at a dosage of $25 \mathrm{IU} \mathrm{kg}^{-1}$ or more, possibly within $6 \mathrm{~h}$ from the event, this treatment being repeated every 12-24 h until complete resolution of the bleeding episode. Breakthrough bleeds occurring in patients enrolled in the prophylaxis arm had to be treated with extra doses of concentrate in the same way. Dosages used in prophylaxis could be adjusted according to the supervisor's judgement, depending on any one of the following variables: occurrence of frequent breakthrough bleeding, vial size (500 IU/vial) and maintenance of FVIII trough levels above $1 \%$. In 2004, Recombinate ${ }^{\circledR}$ was no longer commercially available in Italy, so all patients were switched to a third generation rFVIII (Advate ${ }^{\circledR}$, Baxter, USA).

Treatments were administered by one of the family members at home, as this was common practise in these patients in Italy. The protocol allowed early change of the assigned treatment when it was deemed inadequate by the supervisor, owing to one of the following reasons: a high frequency of bleeding episodes (defined as 3 monthly bleeds or more), development of a target joint (defined as three bleeds in the same joint in a 6-month time period), life-threatening hemorrhage; or bone or cartilage damage on joint imaging. Patients continued to be followed-up and were analysed on intention-to-treat basis. Patients were removed at the time of development of inhibitors or withdrawal of participation consent or when lost to follow-up.

\section{Outcomes}

The primary endpoint pertaining to efficacy was the overall frequency of clinically significant bleeding events (defined as 
bleeding events requiring replacement therapy) and the occurrence and severity of joint damage (as ascertained by plain film radiography of elbows, knees and ankles). Frequency of bleeding was chosen as the primary outcome because it is correlated with a worse orthopedic outcome [8], so it is a reliable short-term surrogate marker of efficacy. The caregivers were asked to fill in a patient diary reporting date, time and site of bleeding, which required treatment, date and time of concentrate infusion and units infused. Patients' diaries were then reviewed with the caregivers every 3 months.

In addition, a second primary outcome was included (i.e. the radiologic changes of the most frequently involved joints). Radiologic evaluation, scheduled at study entry, every 2.5 years and at the end of the follow-up period, was carried out according to the Pettersson radiologic score [13], which takes mainly into account joint structural changes. Radiograms were evaluated by an independent radiologist (BL), unaware of the treatment arm. The study was planned to last 10 years from the time of enrollment of the first patient.

Secondary analyses were carried out on the frequency of hemarthroses, presence of clinical signs of musculoskeletal involvement, compliance, inhibitor development, need for the use of central venous catheters and related complications, trough FVIII levels (in the prophylaxis arm), overall amount of concentrates used, direct costs and health-related quality of life (HRQoL). The orthopedic assessment of elbows, knees and ankles was carried out every year, according to the World Federation of Hemophilia Orthopaedic Joint Score [14], which takes into account range of motion, presence of muscular atrophy, presence of chronic synovitis or deformity. This evaluation was performed by a trained clinician in each centre, who was unaware of the treatment group. Feasibility of treatment and patient compliance were evaluated throughout the trial period in terms of number of bleeding episodes not properly treated (delayed or missed treatment), number of missed infusions, efficiency and adequacy of any needed subcutaneous venous port and patient and family acceptance of the assigned treatment. Compliance with study medication was assessed by requesting patients' parents to record all infusions and bleeding episodes and their treatment in a special diary and checking it at each visit at the hemophilia centre. In cases of apparently poor compliance, instructions were reinforced and checked at appropriate intervals. In patients randomized to prophylaxis, plasma levels of FVIII coagulant activity were obtained every 6 months immediately prior to one of the regularly scheduled infusions, in order to determine if trough levels were above $1 \%$. In the case of FVIII levels being lower than or equal to $1 \%$, the dose regimen had to be adjusted by increasing the dose of the infusion before the longest interval or of each infusion up to $40 \mathrm{IU} \mathrm{kg}{ }^{-1}$. These evaluations were performed on the most critical day (for example, on Monday, when the schedule was Monday, Wednesday, Friday). Plasma for FVIII recovery (30 min post-infusion) and inhibitor levels were carried out every month for the first 6 months, every 3 months for the following 18 months, every year thereafter and whenever the treating physician felt that there was a poor clinical response to FVIII infusion.

Cost evaluation was mainly based on the annual FVIII consumption, which accounts for up to $95 \%$ of the overall costs $[15,16]$. Although the general perspective adopted in this study is a societal one, health care resources absorbed by thecare of patients were specifically considered. Hence, resources absorbed have been quantified into monetary terms adopting the perspective of the third party payer (i.e. the Italian National Health Service (NHS)). All costs are expressed in Euros as at 2010.

The psychological impact in patients and their families was compared in the two treatment arms only at the end of the follow-up period by means of a disease-specific QoL questionnaire (Haemo-QoL) [17]. The Haemo-QoL questionnaire is available as a self-report instrument for children of three different age groups (I, 4-7; II, 8-12; III, 13-16 years) and as corresponding proxy versions for parents. Item responses of age groups II and III are scored on a five-point Likert scale between 1 and 5 (ranging from 'never' to 'always'). Self-ratings and proxy versions were administered to children of age groups II and III and to their parents. The Haemo-QoL provides values for the subscales and the total scale ranging from 0 to 100, with a high value indicating a high impairment in QoL.

\section{Sample size}

The sample size was calculated on the predicted bleeding frequency. Based on literature reports[18], we assumed that the bleeding frequency in children was 1.5 monthly bleeds per patient treated episodically (and a standard deviation of 1.0 bleed) and 0.5 monthly bleeds in children treated prophylactically, a difference judged as clinically relevant. Based on $80 \%$ power to detect a significant difference $(P=0.05$, two-sided $)$, 16 patients were required for each study group. To compensate for potentially not evaluable patients (about one-third), we planned to enrol at least 22 patients per group.

\section{Statistics}

As a pragmatic design was chosen [12], all data analysis was carried out on an intention-to-treat basis, according to a preestablished analysis plan. Descriptive statistics were used to depict the study population. Proportions were compared by using chi-squared tests with continuity correction, or Fisher's exact test when appropriate. Analysis of variance was used to evaluate differences between the two study arms. Two-sided significance tests were used throughout. This report adheres to the recommendations of the CONSORT group (Appendix 2) [19] and its extension to pragmatic trials [20].

\section{Results}

\section{Enrollment and follow-up}

The enrollment period was December 1996 to December 1999. Seventy-two patients were assessed for eligibility in a 
consecutive and competitive fashion (Milan, 14; Rome, 10; Bari, 9; Naples, 7; Bolzano, 5; Genoa, 5; Castelfranco V., 4; Catania, 4; Florence, 4; Palermo, 4; Parma, 3; Vicenza, 3). Of these, 17 were excluded because of unmet inclusion criteria (nine parents refused randomization, three patients had suffered from more than two bleeding episodes in the same joints, three patients had not bled in the previous 6 months, one child had radiologic signs of arthropathy, and one child belonged to an unreliable (dysfunctional) family). As soon as the planned number of patients was achieved patient enrollment stopped. Forty-five patients were ultimately enrolled (Fig. 1): 23 were randomized to prophylaxis and 22 to episodic therapy. Five of them withdrew their consent immediately after knowing their treatment assignment: two randomized to prophylaxis, three to episodic therapy. They did not allow us to use any data concerning their clinical status; therefore, they could not be included in the intent-to-treat analysis. Forty patients effectively received study treatments (Table 1). Four patients in each arm chose to discontinue the follow-up during the study. Five additional patients discontinued treatment for inhibitor development (see below). Four patients in the prophylaxis arm and five in the episodic therapy arm discontinued the assigned treatment and switched to the other after 49-87 months (mean, 62 months): they continued to be regularly followed. All analyses were carried out by 'intention-to-treat'. The median follow-up was 82.5 months, ranging from 2 to 163 months; 84.4 months (min-max, 2-96 months) in patients randomized to prophylaxis and 81.9 months (min-max, 13-163 months) in patients randomized to episodic therapy.

\section{Outcomes}

Children randomized to prophylaxis had a significantly smaller number of all bleeding episodes and joint bleeding episodes compared with those randomized to the episodic therapy
(Table 2). Figure 2 shows the bleeding distribution in the two treatment groups: 11 of 21 patients $(52 \%)$ in the prophylaxis group had on average $<1$ hemarthrosis per year, whereas only 4 of 19 patients in the episodic therapy group (21\%) had the same low frequency of bleeding $(P<0.05)$. Patients randomized to prophylaxis aged 3 years or less at study entry had a much lower incidence of all bleeds $(0.35$ events per patient per month) and joint bleeds ( 0.12 events per patient per month) than patients older than 3 years at assignment (0.62 and 0.25 events per patient per month). None of the patients who started prophylaxis at the age of 3 years or earlier had on average more than three bleeds per year, compared with 5 of 13 patients who started prophylaxis later (38\%). Bleeding was more frequent in ankles, followed by elbows, knees, shoulders and hips (Fig. 3). All bleeding episodes were treated with a median dose of $26.8 \mathrm{IU} \mathrm{kg}^{-1}$ (min-max, 14-100 IU kg ${ }^{-1}$ ), with no difference between the two treatment groups.

Radiologic evaluation showed signs of hemophilic arthropathy in six patients randomized to prophylaxis (29\%) (median Pettersson score 5; range, 3-14) and in 14 of those randomized to episodic therapy $(74 \%)$ (median Pettersson score 8 ; range, $2-$ 12) $(P<0.05)$. Prophylaxis was more effective when started at younger ages. Indeed, none of the eight patients who started prophylaxis at the age of 36 months or less had radiologic signs of arthropathy, compared with 6 of the 13 older children on prophylaxis $(46 \%, P<0.05)$. Of patients randomized to episodic therapy, four of seven $(57 \%)$ aged 36 months or less and 10 of $12(83 \%)$ of the older children had radiologic signs of joint damage. The most frequently involved joints were elbows and ankles, followed by knees. No alterations were found in shoulders and hips.

A statistically significant difference was found for bleeding frequency between joints with and without subsequent radiologic signs of damage $(P<0.05)$; no correlation was found between number of bleeds in each joint and Pettersson's score.

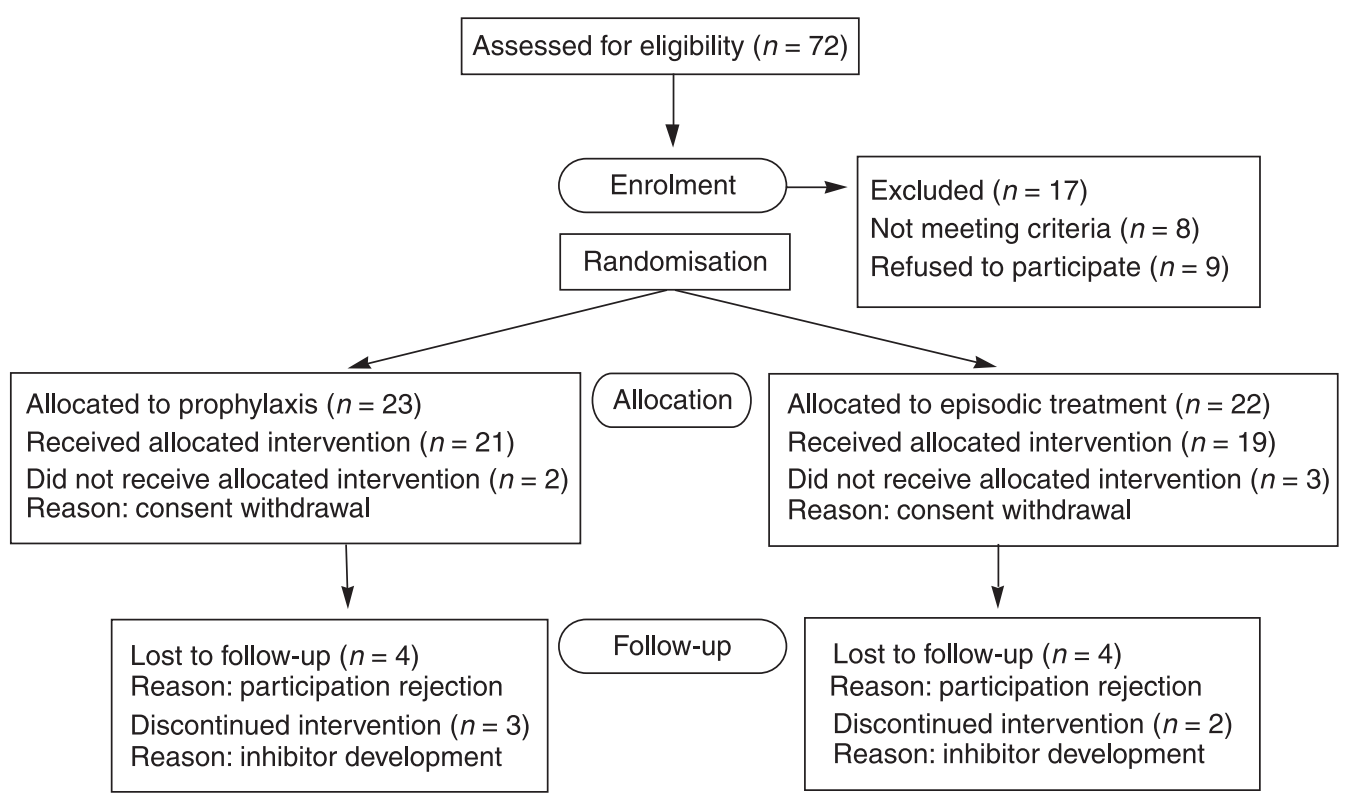

Fig. 1. Flow diagram of participants through each stage of the study. 
Table 1 Baseline demographic characteristics of trial groups

\begin{tabular}{|c|c|c|c|}
\hline Characteristic & $\begin{array}{l}\text { Prophylaxis } \\
(n=21)\end{array}$ & $\begin{array}{l}\text { Episodic } \\
\text { treatment }(n=19)\end{array}$ & $P$ value \\
\hline \multicolumn{4}{|l|}{ Age, months } \\
\hline Mean $\pm \mathrm{SD}$ & $49.7 \pm 26.9$ & $48.8 \pm 21.2$ & \multirow[t]{2}{*}{ ns } \\
\hline Median (min-max) & $50(10-84)$ & $48(14-84)$ & \\
\hline \multicolumn{4}{|c|}{ Age groups, $n(\%)$} \\
\hline$\leq 36$ months & $8(38)$ & $7(38)$ & \multirow[t]{3}{*}{ ns } \\
\hline 37-60 months & $6(29)$ & $6(32)$ & \\
\hline$>60$ months & $7(33)$ & $6(32)$ & \\
\hline \multicolumn{4}{|c|}{ Age at diagnosis, months } \\
\hline Mean \pm SD & $5.7 \pm 6.2$ & $8.8 \pm 10.1$ & \multirow[t]{2}{*}{ ns } \\
\hline Median (min-max) & $6(0-23)$ & $6(0-32)$ & \\
\hline \multicolumn{4}{|c|}{ Body mass index, $\mathrm{kg} \mathrm{m}^{-2}$} \\
\hline Mean \pm SD & $16.4 \pm 0.8$ & $16.4 \pm 0.7$ & \multirow[t]{2}{*}{ ns } \\
\hline Median (min-max) & $16.2(15.5-18.2)$ & $15.5(15.5-17.9)$ & \\
\hline
\end{tabular}

$\mathrm{SD}$, standard deviation.

ns, not significant.

Table 2 Outcome data. Patients are divided on the basis of randomization

\begin{tabular}{|c|c|c|c|}
\hline Variable & $\begin{array}{l}\text { Prophylaxis } \\
(n=21)\end{array}$ & $\begin{array}{l}\text { Episodic } \\
\text { treatment } \\
(n=19)\end{array}$ & $P$ value \\
\hline \multicolumn{4}{|l|}{ No. of months in study } \\
\hline Mean & 72.5 & 76.0 & \multirow[t]{3}{*}{ ns } \\
\hline Median (min-max) & $81.9(2-96)$ & $84.4(13-163)$ & \\
\hline No. of patient years & 127 & 120 & \\
\hline \multicolumn{4}{|c|}{ Age at the end of the study (months) } \\
\hline Mean & 122.2 & 124.8 & \multirow[t]{2}{*}{ ns } \\
\hline Median (min-max) & $148(18-193)$ & $154(27-204)$ & \\
\hline \multicolumn{4}{|c|}{ Total bleeding events per patient } \\
\hline Mean & 37.9 & 82.4 & \multirow[t]{3}{*}{$<0.01$} \\
\hline Median (min-max) & $25(0-233)$ & $76(0-305)$ & \\
\hline $\begin{array}{l}\text { Mean no. of events } \\
\text { per patient } \\
\text { per month }\end{array}$ & 0.52 & 1.08 & \\
\hline $\begin{array}{l}\text { Median no. of events per } \\
\text { patient per year }\end{array}$ & 4.0 & 12.0 & \\
\hline \multicolumn{4}{|c|}{ No. of hemarthroses per patient } \\
\hline Mean & 14.7 & 40 & \multirow{4}{*}{$<0.01$} \\
\hline Median (min-max) & $7(0-68)$ & $36(0-117)$ & \\
\hline $\begin{array}{l}\text { Mean no. of events per } \\
\text { patient per month }\end{array}$ & 0.20 & 0.53 & \\
\hline $\begin{array}{l}\text { Median no. of events per } \\
\text { patient per year }\end{array}$ & 1.0 & 5.5 & \\
\hline \multicolumn{4}{|l|}{ Radiographic findings } \\
\hline $\begin{array}{l}\text { Patients with joint } \\
\text { damage, no. }(\%)\end{array}$ & $6(29 \%)$ & $14(74 \%)$ & \multirow[t]{2}{*}{$<0.05$} \\
\hline $\begin{array}{l}\text { Patients without joint } \\
\text { damage, no. }\end{array}$ & 15 & 5 & \\
\hline \multicolumn{4}{|c|}{ Overall FVIII concentrate usage per infusion (IU kg ${ }^{-1}$ per infusion) } \\
\hline Mean & 31.7 & 31.7 & \multirow[t]{2}{*}{ ns } \\
\hline Median (min-max) & $26.9(14-157)$ & $26.3(7-208)$ & \\
\hline \multicolumn{4}{|c|}{ Total no. of FVIII units infused } \\
\hline Prophylaxis & 12239,873 & 3961478 & $<0.01$ \\
\hline Joint bleeding & 304732 & 701775 & $<0.01$ \\
\hline Total & 13477251 & 5749085 & $<0.01$ \\
\hline
\end{tabular}

ns, not significant.

Given the number of participants from each arm that changed their treatment regimens during the period of study, bleeding and radiologic data were reanalyzed according to actual

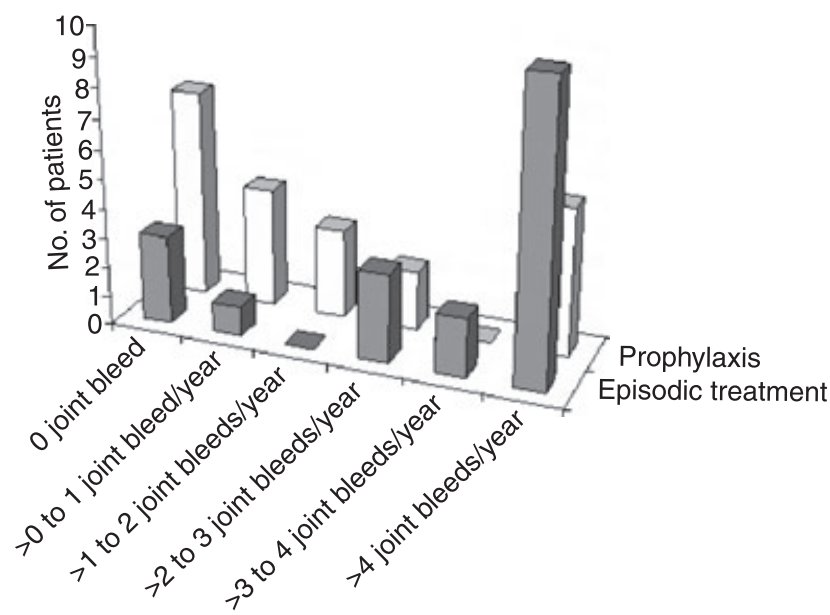

Fig. 2. Patient distribution according to the observed average number of joint bleeds per year and treatment arm. Grey columns represent patients on episodic treatment. White columns represent patients on prophylaxis.

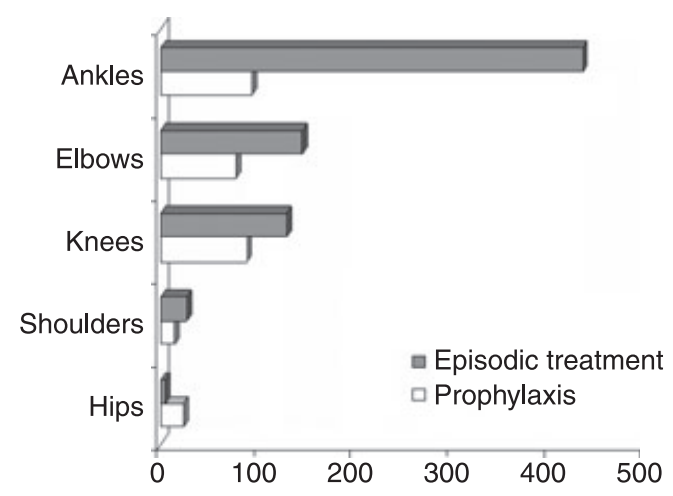

Fig. 3. Total number of joint bleeding events according to the sites of occurrence and treatment arm.

treatment (patients are censored at treatment switch or study discontinuation, whichever came first, Table 3).

\section{Secondary analyses}

None of the eight patients randomized to prophylaxis at the age of 3 years or less had clinical signs of joint damage compared to 3 of 10 patients of same age randomized to episodic therapy; 2 of 13 patients from the prophylaxis group older than 3 years showed some signs of joint involvement, and 2 of 9 of those on episodic therapy of the same age. No correlation was found with bleeding frequency.

Less than $2 \%$ of the overall prescribed infusions were missed. The recommended prophylactic dose of rFVIII (25 IU kg ${ }^{-1}$ body weight) was sufficient to maintain FVIII levels above $1 \%$ in 7 of 18 patients on prophylaxis $(35 \%)$ without inhibitors. Two patients had to increase the threetimes-weekly dose to $30-40 \mathrm{IU} \mathrm{kg}^{-1}$ independently from the trough level, owing to a high frequency of bleeding. Five had to increase the dose of the infusion with a longer interval before the following infusion to $30-40 \mathrm{IU} \mathrm{kg}^{-1}$ in order to maintain 
Table 3 Bleeding events and radiographic data by actual treatment (patients are censored at treatment switch or study discontinuation, whichever came first)

\begin{tabular}{|c|c|c|c|}
\hline Variable & $\begin{array}{l}\text { Prophylaxis } \\
(n=21)\end{array}$ & $\begin{array}{l}\text { Episodic } \\
\text { Treatment } \\
(n=19)\end{array}$ & $P$ value \\
\hline \multicolumn{4}{|c|}{ No. of months in randomization arm } \\
\hline Mean & 46.2 & 51.8 & ns \\
\hline Median (min-max) & 54.5 & 58.6 & \\
\hline No. of patient years & 81 & 82 & \\
\hline \multicolumn{4}{|c|}{ Total bleeding events per patient } \\
\hline Mean & 5.0 & 24.9 & $<0.01$ \\
\hline Median (min-max) & 1 & 7.5 & \\
\hline $\begin{array}{l}\text { No. of events per patient } \\
\text { per month }\end{array}$ & 0.11 & 0.48 & \\
\hline \multicolumn{4}{|l|}{ No. of hemarthroses per patient } \\
\hline Mean & 2.48 & 12.42 & $<0.01$ \\
\hline Median (min-max) & 0 & 4 & \\
\hline $\begin{array}{l}\text { No. of events per patient } \\
\text { per month }\end{array}$ & 0.05 & 0.24 & \\
\hline \multicolumn{4}{|l|}{ Radiographic findings } \\
\hline Joint damage, no. (\%) & 0 & 5 & ns \\
\hline No joint damage, no. (\%) & 21 & 14 & \\
\hline
\end{tabular}

ns, not significant.

FVIII levels above $1 \%$; the remaining four patients continued with the same dose despite trough FVIII levels below $1 \%$. No correlation was found between bleeding frequency and trough FVIII levels.

Monthly factor usage per patient month was $8852 \mathrm{IU}$ in patients on prophylaxis vs. $3981 \mathrm{IU}$ in patients on episodic therapy. With an average price per IU of recombinant FVIII concentrates of $0.75 €$, the yearly cost of prophylaxis was $79668 €$ compared with $35829 €$ on episodic therapy. The incremental cost-efficacy ratio per bleeding event avoided in patients on prophylaxis was $7537 €(10049.6 \mathrm{IU} \times 0.75 €)$. The incremental cost-efficacy ratio for maintaining all joints pristine over the whole treatment period was $201601.12 €$ $(268801.5 \mathrm{IU} \times 0.75 €)$.

QoL as evaluated by children and adolescents was on average good, with a total Haemo-QoL score of 29.97 $(\mathrm{SD}=9.3)$ for both age groups together, with similar ratings given by parents (mean 28.70, SD $=11.2$ ). Children and adolescents, as well as their parents, reported mainly impairments in the dimension 'friends' (mean 56.3, SD = 22.2), 'perceived support' (mean 52.92, SD $=30.2$ ) and 'dealing' (mean 51.15, $\mathrm{SD}=33.1$ ).

A significant difference was found between children and adolescents on episodic treatment vs. prophylaxis for the dimension 'family' (Student's $t$-test, $P<0.029$ ), which was more impaired in the episodic treatment (mean 44.0, SD 22.6) than in the prophylaxis group (mean 11.27, SD 8.7) (Fig. 4). No difference was revealed between the treatment groups in the parents' ratings. Moreover, children on episodic treatment felt 'often' or 'always' more overprotected both by their mother $(80 \%$ vs. $11 \%)$ and father $(80 \%$ vs. $20 \%)$ than children on prophylaxis (Fig. 5). Twenty per cent of children and adoles-

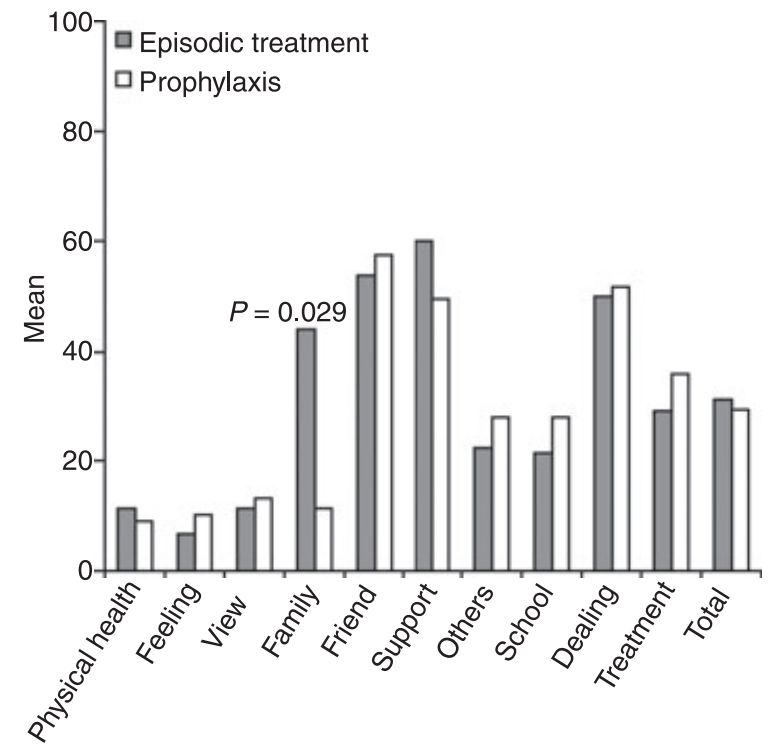

Fig. 4. Comparison between children's and adolescents' QoL (age groups II and III) by means of the Haemo-QoL across treatment regimes: prophylaxis (grey bars) and episodic treatment (black bars).

cents on episodic treatment perceived that their parents had 'often' or 'always' to limit their time at work or leisure because of their hemophilia compared with none in the prophylaxis group, where only $10 \%$ of children perceived that their parents had only 'sometimes' their work or leisure time limited.

\section{Adverse events}

Ten of 20 patients on prophylaxis required indwelling catheters $\left(\right.$ Port-a-Cath $\left.{ }^{\circledR}\right)$, whereas none of the patients in the episodic therapy group did. Six patients with indwelling catheters had an infection within 1-60 months from insertion (median 6 months). In two of these patients the catheter was removed and this required hospitalization for 2 days.

Five patients developed inhibitors (12.5\%): three patients were in the prophylaxis group (14.3\%), aged 10, 35 and 63 months at enrollment, and they developed inhibitors after 2-4 months of follow-up, after 24-48 exposure days. The remaining two patients with inhibitors were in the episodic therapy group (10.5\%), aged 19 and 49 months, and they developed inhibitors after 13 and 24 months, at 20 and 24 exposure days. Patients with inhibitors in the prophylaxis group had indwelling catheters and one of them had developed an infection 2 weeks before inhibitor occurrence, whereas none of the patients with inhibitors in the episodic group had central venous access or had undergone surgery or intensive treatment. No patient suffered from life- or limb-threatening bleeding events or from bleeding events that required hospitalization.

\section{Discussion}

This randomized controlled trial was designed to evaluate the impact of two treatment options in a population of young 


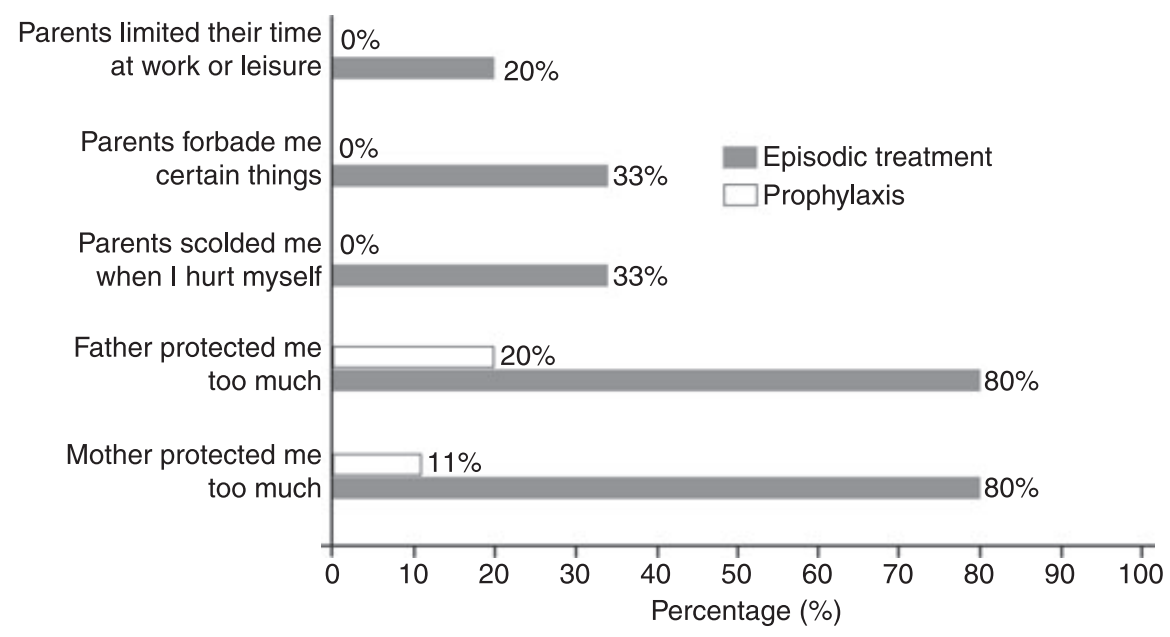

Fig. 5. Frequency of answers 'often/always' to items in the dimension 'family' of the self-report of children and adolescents of the Haemo-QoL across treatment regimes. Grey columns represent patients on episodic treatment. White columns represent patients on prophylaxis.

children with severe hemophilia. The design of the study, the study population (with a relatively broad range of ages), the modalities of treatment (episodic therapy vs. prophylactic infusions three times weekly), the primary and secondary outcomes, and the type of analysis by intention-to-treat were all chosen with the goal of evaluating the benefit of prophylaxis from a pragmatic point of view [12]. The aim was not only to gather more evidence on the superiority of prophylaxis, which at the time of this study stemmed only from the evaluation of retrospective cohorts, but also to provide more information that might help all the stakeholders in hemophilia care (namely patients, physicians and budget holders) to make evidencebased decisions.

Prophylaxis at the average dose of $30 \mathrm{IU} \mathrm{kg}^{-1}$ three times a week was able to significantly reduce the overall bleeding frequency, and in particular that due to hemarthroses. The mean incidence of joint bleeding was relatively high (0.20 events per patient per month) if compared with that of other cohorts of patients [9,21]. In particular, the Joint Outcome Study (JOS) [9], found a 4-fold lower incidence ( 0.05 events per patient per month) in patients on prophylaxis. This difference is perhaps explained by the different ages at enrollment of the two study populations: ours included patients up to 7 years of age, while the JOS only included patients aged up to 2.5 years. In the subgroup of patients with a younger age (equal to or lower than 3 years) the incidence was only 0.12 events per patient per month (i.e. much closer to that observed in the JOS). In addition, one should take into account the longer follow-up of our study as well as the intention-totreat analysis that did not exclude patients who switched treatment during the study.

Our study shows that prophylaxis was able to reduce the risk of joint damage. The image-proven evidence of arthropathy was observed in three-quarters of the patients randomized to episodic therapy, compared with only one-quarter of those randomized to prophylaxis. Patients who started prophylaxis at the age of 3 years or less showed more pristine joints.
Nevertheless, those children who initiated prophylactic treatment after the third year of age also benefited from prophylaxis. Compared with the JOS findings, our study found a higher percentage of patients with radiologic evidence of joint damage, due to the older population recruited and perhaps also to the much longer follow-up. Prophylaxis was able to reduce the risk of joint damage also in those patients who started prophylaxis at later ages, although with lower efficacy. This is the first prospective and controlled trial that provides direct evidence that early prophylaxis (i.e. prophylaxis started in the first years of life) is more effective than delayed prophylaxis, in agreement with previous retrospective studies $[3,6,22]$. These findings are partially in contrast to the recently published German retrospective study by Schobess et al. [23], who compared primary versus secondary prophylaxis started early. These authors found no statistical difference in imaging-proven hemophilic joint damage between the two populations, but those populations had quite wide age ranges (0.1-6.7 and 0.816 years, respectively), which are likely to have influenced the results because of poorly homogeneous populations.

In addition, the present study provides further evidence on the high rate of infectious complications of indwelling catheters, which according to some data [24] may represent one of the risk factors of inhibitor development: $60 \%$ of our patients with Port-a-Caths had catheter and systemic infections, and one of these patients developed an inhibitor a few days after infection occurrence. According to our experience, venous access probably represents the major barrier to prophylaxis, and central venous devices are not a reliable solution, the patients being exposed to a high rate of complications [25]. This issue has prompted either the use of arterio-venous fistulas [26], or the implementation of prophylaxis that adopts an escalating frequency of infusion [21].

As expected, the cost of prophylaxis is more than double that of episodic therapy. Similar figures have been found by others $[9,15,27]$, with differences between the two costs of treatment options ranging from 2.4-fold [9] to 3.1-fold [27]. The 
incremental cost-effectiveness ratio per bleed avoided showed the need for a high investment of resources (7537€), much higher than that reported by the only other study that carried out a cost-effectiveness analysis of prophylaxis in children based on empiric data [27]. The huge difference is probably due to the design of that study (retrospective, non-randomized) and the shorter length of the time period of data collection ( 2 years). Furthermore, we calculated how much expenditure on average is required to maintain pristine joints in a child with hemophilia: about $200000 €$ over a period of approximately 7 years (about $2500 €$ monthly).

QoL was found to be significantly worse in children on episodic treatment in the dimension 'family'. Indeed, children on episodic treatment complained about the overprotection of their parents and reported that their parents had to limit their time at work or leisure. It would seem that prophylaxis gives parents definite reassurance, so that they do not have the need to look after their children in the same obsessive manner seen in parents of children treated episodically, who are afraid that their children could hurt themselves and bleed. These findings are similar to those from the European Haemo-QoL study [28], where in general prophylaxis seemed to be associated with less impairment in QoL. It can be argued that prophylaxis should be expected to have a greater positive impact on children's QoL. Small children might not be able to grasp the benefits of this burdensome treatment and are more troubled by the pain and the time spent having the injections.

Strengths of this study are the randomized controlled design, the intention-to treat analysis, the pragmatic approach, with a relatively broad range of patients with different ages at study entry and with modalities of treatment that reflect the common practise, an approach that provides information that can be extrapolated to all children with hemophilia, and the longest follow-up so far. Limits are represented by the relatively small number of hemophilia patients selected from a relatively low number of children, even though the competitive and consecutive enrollment should have limited selection biases. Other limits are the use of plain-film radiography and of the WFH Orthopedic Joint Score, because these two methods are relatively insensitive to early orthopedic alterations in children. We have not considered the cost of catheter infections in the 10 patients on prophylactic treatment. However, this cost can be considered negligible, when compared with the overall cost of clotting factors: even assuming that all infections lead to a catheter replacement, this would increase the total prophylaxis cost by about $0.02 \%$ to $0.2 \%$, given the current cost of catheter implantation [29]. Another limitation is that QoL was tested only at the end of the study, because the HaemoQoL was not available at the time of patient enrollment and only some of the patients were willing to complete the questionnaire.

In conclusion, this study confirms by means of a randomized design the efficacy of prophylaxis in preventing bleeding and image-proven arthropathy in children with severe hemophilia. Moreover, it confirms that early prophylaxis is more efficacious than delayed prophylaxis, even though the latter still generates substantial benefits to these patients. The higher costs of prophylaxis compared with episodic therapy are balanced by a better orthopedic outcome and hence a better quality of life.

\section{Addendum}

A. Gringeri and P. M. Mannucci designed the research, analysed data and wrote the paper. B. Lundin performed Xray evaluation and analysed data. L. Mantovani performed pharmacoeconomic analyses. S. von Mackensen performed quality of life analyses. All authors reviewed the paper.

\section{Acknowledgements}

Thanks to the ESPRIT Study Group for its active and essential participation in this study (a complete membership list appears in Appendix 1) and to the participating patients and their families. This work was supported by an unrestricted grant from Baxter Italy to cover the cost of the Contract Research Organisation, hired for the trial monitoring, data management and data analysis. No company had access to the data, or participated in the analysis and/or the discussion of results. None of the authors and the members of the ESPRIT group have received any other kind of grant, fee or compensation for the study.

\section{Disclosure of Conflict of interest}

A. Gringeri has received: research grants from Baxter, Biotest, CSL Behring and Grifols; speaker fees from Baxter, Biotest, CSL Behring, Grifols, Kedrion, Novo Nordisk, Octapharma and Wyeth; and consulting fees from Baxter and Wyeth. B. Lundin has received: reimbursement for attending a symposium from Wyeth Pharmaceuticals and Bayer Healthcare; and a fee for speaking and a fund for research from Bayer Healthcare. S. von Mackensen has received: research grants from CSL Behring, Novo Nordisk, Octapharma and Wyeth; and speaker fees from Bayer and Kedrion; no consultation fee from either company. L. Mantovani has received: research grants from Bayer, CSL Behring, Grifols, Kedrion, Novo Nordisk and Wyeth; speaker fees from Baxter, Bayer and Novo Nordisk; no consultation fee from either company. P. M. Mannucci has received: speaker fees from Baxter, Bayer, Biotest, CSL Behring, Grifols, Novo Nordisk and Wyeth; consulting fees from Kedrion and Wyeth; no research grant from either company.

\section{References}

1 Roosendaal G, Jansen NW, Schutgens R, Lafeber FP. Haemophilic arthropathy: the importance of the earliest haemarthroses and consequences for treatment. Haemophilia 2008; 14(Suppl. 6): 4-10.

2 Darby SC, Kan SW, Spooner RJ, Giangrande PL, Hill FG, Hay CR, Lee CA, Ludlam CA, Williams M. Mortality rates, life expectancy, and causes of death in people with haemophilia A or B in the United Kingdom who were not infected with HIV. Blood 2007; 110: 815-25. 
3 Nilsson IM, Berntorp E, Löfqvist T, Pettersson H. Twenty-five years' experience of prophylactic treatment in severe haemophilia A and B. J Intern Med 1992; 232: 25-32.

4 Berntorp E, Astermark J, Björkman S, Blanchette VS, Fischer K, Giangrande PL, Gringeri A, Ljung RC, Manco-Johnson MJ, Morfini M, Kilcoyne RF, Petrini P, Rodriguez-Merchan EC, Schramm W, Shapiro A, van den Berg HM, Hart C. Consensus perspectives on prophylactic therapy for haemophilia: summary statement. Haemophilia 2003; 9(Suppl. 1): 1-4.

5 Donadel-Claeyssens S. European Paediatric Network for Haemophilia Management. Current co-ordinated activities of the PEDNET (European Paediatric Network for Haemophilia Management). Haemophilia 2006; 12: 124-7.

6 Astermark J, Petrini P, Tengborn L, Schulman S, Ljung R, Berntorp E. Primary prophylaxis in severe haemophilia should be started at an early age but can be individualized. Br J Haematol 1999; 105: 1109 13.

7 Stobart K, Iorio A, Wu JK. Clotting factor concentrates given to prevent bleeding and bleeding-related complications in people with hemophilia A or B. Cochrane Database Syst Rev 2005; 2: CD003429.

8 Aledort LM, Haschmeyer RH, Pettersson H. A longitudinal study of orthopaedic outcomes for severe factor-VIII-deficient haemophiliacs. The Orthopaedic Outcome Study Group. J Intern Med 1994; 236: 3919.

9 Manco-Johnson MJ, Abshire TC, Shapiro AD, Riske B, Hacker MR, Kilcoyne R, Ingram JD, Manco-Johnson ML, Funk S, Jacobson L, Valentino LA, Hoots WK, Buchanan GR, DiMichele D, Recht M, Brown D, Leissinger C, Bleak S, Cohen A, Mathew P, et al. Prophylaxis versus episodic treatment to prevent joint disease in boys with severe hemophilia. $N$ Engl J Med 2007; 357: 535-44.

10 Royal S, Schramm W, Berntorp E, Giangrande P, Gringeri A, Ludlam C, Kroner B, Szucs T; for the European Haemophilia Economics Study Group. Quality-of-life differences between prophylactic and ondemand factor replacement therapy in European haemophilia patients. Haemophilia 2002; 8: 44-50.

11 Gringeri A, von Mackensen S. Quality of life in haemophilia. Haemophilia 2008; 14(Suppl. 3): 19-25.

12 Schwartz D, Lellouch J. Explanatory and pragmatic attitudes in therapeutical trials. J Chronic Dis 1967; 20: 637-48.

13 Pettersson H. Radiographic scores and implications. Semin Hematol 1993; 30(3 Suppl 2): 7-9.

14 Gilbert MS. Prophylaxis: musculoskeletal evaluation. Semin Hematol 1993; 30(3 Suppl 2): 3-6.

15 Smith PS, Teutsch SM, Shaffer PA, Rolka H, Evatt B. Episodic versus prophylactic infusions for hemophilia A: a cost-effectiveness analysis. J Pediatr 1996; 129: 424-31.

16 Globe DR, Curtis RG, Koerper MA. Utilization of care in haemophilia: a resource-based method for cost analysis from the Haemophilia Utilization Group Study (HUGS). Haemophilia 2004; 10(Suppl. 1): $63-70$.
17 von Mackensen S, Bullinger M; Haemo-QoL Group. Development and testing of an instrument to assess the Quality of Life of Children with Haemophilia in Europe (Haemo-QoL). Haemophilia 2004; 10(Suppl. 1): 17-25.

18 Perrin JM, MacLean WE Jr, Janco RL, Gortmaker SL. Stress and incidence of bleeding in children and adolescents with hemophilia. $J$ Pediatr 1996; 128: 82-8.

19 Moher D, Schulz KF, Altman DG. The CONSORT statement: revised recommendations for improving the quality of reports of parallel-group randomised trials. Lancet 2001; 357: 1191-4.

20 Zwarenstein M, Treweek S, Gagnier JJ, Altman DG, Tunis S, Haynes B, Oxman AD, Moher D: CONSORT group; Pragmatic Trials in Healthcare (Practihc) group. Improving the reporting of pragmatic trials: an extension of the CONSORT statement. BMJ 2008; 337: a2390.

21 Feldman BM, Pai M, Rivard GE, Israels S, Poon MC, Demers C, Robinson S, Luke KH, Wu JK, Gill K, Lillicrap D, Babyn P, McLimont M, Blanchette VS; Association of Hemophilia Clinic Directors of Canada Prophylaxis Study Group. Tailored prophylaxis in severe hemophilia A: interim results from the first 5 years of the Canadian Hemophilia Primary Prophylaxis Study. J Thromb Haemost 2006; 4: 1228-36.

22 Fischer K, van der Bom JG, Mauser-Bunschoten EP, Roosendaal G, Prejs R, de Kleijn P, Grobbee DE, van den Berg M. The effects of postponing prophylactic treatment on long-term outcome in patients with severe hemophilia. Blood 2002; 99: 2337-41.

23 Schobess R, Kurnik K, Friedrichs F, Halimeh S, Krümpel A, Bidlingmaier C, Nowak-Göttl U. Effects of primary and secondary prophylaxis on the clinical expression of joint damage in children with severe haemophilia A. Results of a multicenter non-concurrent cohort study. Thromb Haemost 2008; 99: 71-6.

24 Oldenburg J, Schröder J, Brackmann HH, Müller-Reible C, Schwaab R, Tuddenham E. Environmental and genetic factors influencing inhibitor development. Semin Hematol 2004; 41(Suppl. 1): 82-8.

25 Valentino LA, Ewenstein B, Navickis RJ, Wilkes MM. Central venous access devices in haemophilia. Haemophilia 2004; 10: $134-46$.

26 Santagostino E, Gringeri A, Berardinelli L, Beretta C, Muça-Perja M, Mannucci PM. Long-term safety and feasibility of arteriovenous fistulae as vascular accesses in children with haemophilia: a prospective study. Br J Haematol 2003; 123: 502-6.

27 Fischer K, van den Berg M. Prophylaxis for severe haemophilia: clinical and economical issues. Haemophilia 2003; 9: 376-81.

28 Gringeri A, von Mackensen S, Auerswald G, Bullinger M, Perez Garrido R, Kellermann E, Khair K, Lenk H, Vicariot M, Villar A, Wermes C; Haemo-QoL Study. Health status and health-related quality of life of children with haemophilia from six West European countries. Haemophilia 2004; 10(Suppl. 1): 26-33.

29 de Portu S, Mantovani LG, Ravaioli A, Tamburini E, Bollina R, Cozzi C, Grimaldi AM, Testa TE, Bianchessi C, Carteni G. Cost of treatment analysis of metastatic colorectal cancer patients: capecitabine vs 5-fluorouracil based regimens. J Chemother 2010; 22: 125-8. 


\section{Appendix 1}

List of members of ESPRIT study group:

A. Billio (Haematology Department, Ospedale Civile, Bolzano, Italy).

E. Boeri (Haemophilia Centre, Haemato-Oncology Department, IRCCS Giannina Gaslini, Genova, Italy).

G. Castaman (Haemostasis and Thrombosis Centre, Haematology Department, Ospedale S. Bortolo, Vicenza, Italy).

N. Ciavarella (Haemophilia Operative Unit, Azienda Ospedaliera Policlinico, Bari, Italy).

G. Mancuso (Paediatric Haemostasis and Thrombosis Centre, Pediatric Clinic, Ospedale dei Bambini, Palermo, Italy).

M. Morfini (Haemophilia Centre, Careggi Hospital, Firenze, Italy).

M. G. Mazzucconi (Haematology Department, Policlinico Umberto I, Roma, Italy).

R. Musso (Haemophilia and Thrombosis Centre, Azienda Ospedaliera Universitaria Vittorio Emanuele,Ferrarotto, Catania, Italy). M. Muça Perja, S. Riva and E. Santagostino (A. Bianchi Bonomi Haemophilia and Thrombosis Centre, IRCCS Maggiore Policlinico, Mangiagalli, Regina Elena Hospital Foundation, Milan, Italy).

A. Rocino (Haemophilia and Thrombosis Centre, Haematology Unit, S. Giovanni Bosco Hospital, Napoli, Italy).

F. A. Scaraggi (Haemostasis and Thrombosis Centre, University Internal Medicine Unit 'C. Frugoni', Azienda Ospedaliera Policlinico, Bari, Italy);

M. Schiavoni (Haemophilia and Thrombosis Centre, Internal Medicine Unit, Presidio Osped. 'I. Veris delli Ponti', Scorrano, LE, Italy).

G. Tagariello (Transfusion Centre, Ospedale Civile, Castelfranco Veneto, TV,Italy).

A. Tagliaferri (Haemophilia Centre, Dipartimento Polispecialistico Medicina 2, Azienda Ospedaliero-Universitaria di Parma, Parma, Italy).

\section{Appendix 2}

CONSORT Statement 2001 Checklist [19]

\begin{tabular}{|c|c|c|c|}
\hline Paper section and topic & Item & Descriptor & Reported on page \# \\
\hline Title \& Abstract & 1 & $\begin{array}{l}\text { How participants were allocated to interventions } \\
\text { (e.g. 'random allocation', 'randomized' or 'randomly } \\
\text { assigned'). }\end{array}$ & $1-2$ \\
\hline Introduction & 2 & Scientific background and explanation of rationale. & 4 \\
\hline \multicolumn{4}{|l|}{ Background } \\
\hline Methods & 3 & Eligibility criteria for participants and the settings and & 6 \\
\hline Participants & & locations where the data were collected. & \\
\hline Objectives & 5 & Specific objectives and hypotheses. & 6 \\
\hline Interventions & 4 & $\begin{array}{l}\text { Precise details of the interventions intended for each } \\
\text { group and how and when they were actually } \\
\text { administered. }\end{array}$ & 7 \\
\hline Outcomes & 6 & $\begin{array}{l}\text { Clearly defined primary and secondary outcome } \\
\text { measures and, when applicable, any methods used to } \\
\text { enhance the quality of measurements (e.g. multiple } \\
\text { observations, training of assessors). }\end{array}$ & 8 \\
\hline Sample size & 7 & $\begin{array}{l}\text { How sample size was determined and, when applicable, } \\
\text { explanation of any interim analyses and stopping rules. }\end{array}$ & 10 \\
\hline Randomization - sequence generation & 8 & $\begin{array}{l}\text { Method used to generate the random allocation } \\
\text { sequence, including details of any restrictions (e.g. } \\
\text { blocking, stratification) }\end{array}$ & 7 \\
\hline Randomization - allocation concealment & 9 & $\begin{array}{l}\text { Method used to implement the random allocation } \\
\text { sequence (e.g. numbered containers or central } \\
\text { telephone), clarifying whether the sequence was } \\
\text { concealed until interventions were assigned. }\end{array}$ & 7 \\
\hline $\begin{array}{l}\text { Randomization } \\
\text { - implementation }\end{array}$ & 10 & $\begin{array}{l}\text { Who generated the allocation sequence, who enrolled } \\
\text { participants, and who assigned } \\
\text { participants to their groups. }\end{array}$ & 7 \\
\hline Blinding (masking) & 11 & $\begin{array}{l}\text { Whether or not participants, those administering the } \\
\text { interventions, and those assessing } \\
\text { the outcomes were blinded to group assignment. If } \\
\text { done, how the success of blinding } \\
\text { was evaluated. }\end{array}$ & 6 \\
\hline
\end{tabular}


710 A. Gringeri et al

Appendix 2 (Continued)

\begin{tabular}{|c|c|c|c|}
\hline Paper section and topic & Item & Descriptor & Reported on page \# \\
\hline Statistical methods & 12 & $\begin{array}{l}\text { Statistical methods used to compare groups for primary } \\
\text { outcome(s); methods for } \\
\text { additional analyses, such as subgroup analyses and } \\
\text { adjusted analyses. }\end{array}$ & 10 \\
\hline $\begin{array}{l}\text { Results } \\
\text { Participant flow }\end{array}$ & 13 & $\begin{array}{l}\text { Flow of participants through each stage (a diagram is } \\
\text { strongly recommended). Specifi } \\
\text { cally, for each group report the numbers of participants } \\
\text { randomly assigned, receiving } \\
\text { intended treatment, completing the study protocol, and } \\
\text { analyzed for the primary } \\
\text { outcome. Describe protocol deviations from study as } \\
\text { planned, together with reasons. }\end{array}$ & 11 \\
\hline Recruitment & 14 & Dates defining the periods of recruitment and follow-up. & 11 \\
\hline Baseline data & 15 & $\begin{array}{l}\text { Baseline demographic and clinical characteristics of each } \\
\text { group. }\end{array}$ & 11 \\
\hline Numbers analyzed & 16 & $\begin{array}{l}\text { Number of participants (denominator) in each group } \\
\text { included in each analysis and } \\
\text { whether the analysis was by 'intention-to-treat'. State } \\
\text { the results in absolute numbers } \\
\text { when feasible (e.g. } 10 / 20 \text {, not } 50 \% \text { ). }\end{array}$ & 11 \\
\hline Outcomes and estimation & 17 & $\begin{array}{l}\text { For each primary and secondary outcome, a summary of } \\
\text { results for each group, and the } \\
\text { estimated effect size and its precision (e.g. } 95 \% \text { confi- } \\
\text { dence interval). }\end{array}$ & 11 \\
\hline Ancillary analyses & 18 & $\begin{array}{l}\text { Address multiplicity by reporting any other analyses } \\
\text { performed, including subgroup } \\
\text { analyses and adjusted analyses, indicating those pre- } \\
\text { specified and those exploratory. }\end{array}$ & 13 \\
\hline Adverse events & 19 & $\begin{array}{l}\text { All important adverse events or side-effects in each } \\
\text { intervention group. }\end{array}$ & 14 \\
\hline $\begin{array}{l}\text { Discussion } \\
\text { Interpretation }\end{array}$ & 20 & $\begin{array}{l}\text { Interpretation of the results, taking into account study } \\
\text { hypotheses, sources of potential } \\
\text { bias or imprecision and the dangers associated with } \\
\text { multiplicity of analyses and out } \\
\text { comes. }\end{array}$ & 15 \\
\hline Generalizability & 21 & Generalizability (external validity) of the trial findings. & 17 \\
\hline Overall evidence & 22 & $\begin{array}{l}\text { General interpretation of the results in the context of } \\
\text { current evidence. }\end{array}$ & 17 \\
\hline
\end{tabular}

